\title{
THE ROLE OF EMOTIONAL RELIGIOUS DISCOURSES IN DELIBERATIVE DECISION-MAKING AT LOCAL GOVERNANCE LEVEL
}

\author{
Adrian SCHIFFBECK, PhD \\ West University of Timișoara \\ Timișoara/Romania
}

\begin{abstract}
Classical political research shows that the degree of democracy inside a local or national system is measured by the levels of inclusion, effective participation and enlightened understanding: Citizens ' participation stands in the center of a democratic society. One form of participation are deliberative processes, supposed to provide welfare, wellbeing and justice. Often, deliberation is accompanied by passion and includes moral and religious arguments, besides rational ones. Supporters of Habermas' theory of the "ideal speech situation" emphasize rationalistic norms, considering emotions, i.a., as a threat to impartiality. Scholars have approached emotions in relation to deliberative practices considering social movements, policy making, service delivery and user involvement, or health care. The focus of this paper is set on the underexplored research field of emotions and decision making at the local governance level. We look at a public debate from 2007 at the City of Timișoara (Romania), concerning the construction of an Orthodox church in a central neighborhood. Our question is related to the importance of emotional religious arguments for reaching an agreement - to provide welfare, well-being and justice. Research methods are based on discourse and conversation analysis. Results point to a potential significant contribution of passionate religious reasons towards reaching a moral, cognitive and - finally - legal consensus. The necessary conditions for democracy - inclusion, effectiveness and understanding - derive
\end{abstract}


from a morally and emotionally balanced deliberation: consideration for ethical principles, such as cognitive and affective competence, trust and responsibility, coming from all sides involved in the process.

\section{Keywords}

Decision making; deliberation; emotion; local governance; participation; religion.

\section{INTRODUCTION AND BACKGROUND}

"Democracy cannot long survive without communication" (Gastil 2008, 8). Generally, the role of citizens in politics is reduced to expressing their opinion when voting - a periodical civic obligation about the meaning of which they are rarely informed properly. It turns to a permanent isolation from the political scene and agenda, with people showing up at the end of electoral campaigns just to "punch holes next to candidate's names", within "a hypothetic nation of zombie citizens, more likely to eat brain than use them" (Gastil 2008, 4). Rarely, people take their destiny into their own hands and decide to build participatory tools, or take part in top-down initiatives allowing for a better understanding and developing of public policies. When citizens do take a step towards the public sphere, they often become part of deliberative practices, where their word is supposed to be heard and taken into consideration. Deliberation is part of the larger area of political communication and has "a central role in the democratic process" (Gastil 2008, xii), at the macro-, as well as micro level of politics. In this study, we will analyse a particular segment of deliberation: the influence of emotional religious arguments on its outcomes.

Emotions play a "complex and multidimensional role" in politics (EngelkenJorge 2011, 7). In relation to deliberative practices, they have been studied particularly with regard to social movements, policy making, service delivery (Barnes 2008), service user involvement (Hodge 2005), or health care deliberation (Komporozos-Athanasiou and Thompson 2015; Davies, Wetherell and Barnett 2009). A further research frame on this subject considered 
redesigning organizational structures by means of large-group intervention methods - future searches, open spaces and citizens' juries (Saam 2018). A growing number of scholars investigated emotions with regard to political behaviour or mobilization, political judgment, communication and decisionmaking (Engelken-Jorge 2011, 7). However, decision making processes especially at the micro-political level, of the community - have received very little attention in relation to emotionality. Our paper approaches this underexplored research field and, by means of analysing a specific case study, attempts to establish the significance of emotions for the outcomes of a deliberative practice. On the other hand, focus lies on moral and religious arguments to be used by participants in a public debate. Weiberg-Salzman and Willems (2020), March (2013), Eberle (2002) and Rawls (1997), among others, set their attention on the structure and "moral acceptability" of such reasons. The affective, emotional impact of religious rhetoric in public debates has considerably less been observed.

The case study refers to a public debate held in 2007 at the City of Timișoara (Romania) - on the intention of the local Orthodox Church (following requests from inhabitants) to build a parish chapel in a central neighborhood with roughly 8,000 inhabitants, instead of an existing playground (planned to be relocated), next to a school and in the perimeter of some blocks of flats. The City's chief architect, local councilors (politicians) and Church representatives were there to discuss with citizens. It turned to emotional discussions, lasting about 90 minutes, between supporters and opponents of the planned construction. The Local Council finally agreed on the proposal; however, the decision was one month later retracted and consensus was reached by offering a different place to the Church for building the edifice. This article describes the unfolding of the public debate in detail, attempting to reveal the role of the emotional and moral type of discourse in ensuring an inclusive, effective and "enlightened" participatory practice - in the end, in reaching an agreement for the deliberative practice and provide welfare, well-being and justice (the aims of deliberation).

Inclusion, effective participation and enlightened understanding (based on reasonable arguments) - have been highlighted as precursors of a democratic 
society (Dahl, 1989; Gastil 2008, 5). In order for a system - "large nations, small groups or any association that hopes to call itself democratic" (Gastil 2008, 5) - to be considered liberal, it has to include public participation. Dahl (1989) states that a nation is never purely democratic, like a human individual never turns out to be perfect. However, for democracy to function, citizens must have the possibility to express their opinions related to public policies outside the voting booth: They have to be included in decision-making and officials have to ensure that the system is not functioning in a formal manner, but in an effective one (achieving tangible results); last, but not least, arguments have to be put on the table fairly and reasonably, in the sense of the Habermasian enlightened understanding. Strong democracy is, in the end, about talk (Barber, 1984) - not in the sense of random communication, but as a process of expressing and listening to opinions, judging and understanding (Gastil 2008, 19).

Research has consistently marched on the importance of reason in political communication and regarded emotions and moral arguments as intruders in the proper unfolding of a deliberation. Our intention is to verify this assumption and establish the level of significance of emotional religious discourses inside deliberative practices. We do this by means of a qualitative approach, partially based on personal participatory observation, and mainly on conversation and discourse analysis. The article is structured as follows: It starts with the arguments in the literature related to positive and negative effects of emotions in public deliberations, in relation to the three main conditions for a functioning democratic system - inclusion, understanding and effectiveness of participation. Looking further at religious arguments in the theoretical context of emotionality, the paper suggests the concepts of moral and emotional balance, as means for an ethical and effective deliberative process. After a description of the methods, we present the case study, the empirical findings and the conclusions of this research. 


\section{DELIBERATING WITH PASSION}

As a part of political communication, deliberation is seen as a central element in democracy - similar to, but different from democratic deliberation and deliberative democracy (Bächtiger and Parkinson 2019,4) - by means of which citizens are called to state their opinions outside the voting booth and listen to what fellows have to say (e.g., Smith 2009). It is a direct process of involvement in the businesses of a state or of a community, based on dialogue and freedom to reflect and argue on specific subjects. The democratic deliberation, or the process of decision-making, is mainly based on discussions in a reasoned and well-informed manner, with consideration towards equality and respecting the other (List 2018, 463). If we look at deliberative democracy - it comprises a transformation process, where people are supposed to leave self-interest behind, listen to each other and pursue social justice and the common good (e.g., Young 2000; Barnes 2008).

In almost any deliberative forum - including decision-making on local public policies - even if it seems settled down, discussions are accompanied by passion (Thompson and Hoggett 2001, 354; Harvey 2009, 148); they are rarely based solely on reason, with lack of emotional engagement. It is difficult to have a neutral and dispassionate deliberation, when people bring their own, subjective values and experiences to a forum (e.g., Barnes 2008, 2005; Davies, Wetherell and Barnett 2006); tensions are then inevitably being created. For constructing a legitimate deliberation, rationality is decisive. But is an exclusively neutral debate possible? Such a dispute will be the "ideal speech situation", where "no force except that of the better argument is exercised" (Habermas 1975). During this type of deliberation, mainly defined by "sincerity, respect and the neutralization of coercive power" (Martin 2012, 166), reason is supposed to have its first and final word to say in reaching a consensus: a fully symmetric process between discussants, respecting the elementary aspects of dialogue and interaction - "assertion and dispute, revelation and concealment, prescription and conformity" (Habermas 1970, 371). 


\subsection{Inclusiveness and reasonable understanding}

When emotion is allowed to enter the field, there are chances that discussions are perturbed and outcomes are not satisfying: "Fear, hatred, and cruelty, as well as compassion, remorse, and grief" will have a negative effect on impartiality and, consequently, on the quality and legitimacy of the deliberative practice (Hoggett and Thompson 2002, 107; 2001). While these emotions are seen as perturbing the debate, others, such as hope, can have promising effects: "Hope seems to be democratic" (Saam 2018, 770). Granting an "excessive" freedom of speech can lead to coercion and manipulation; you give people the possibility to rhetorically express their feelings and may suddenly face blackmail and deception attempts: "Emotion can be coercive; which is why in the end it must answer to reason" (Dryzek 2000, 3). Being too emotionally loaded, discussions jump out of boundaries and generate a conflict with the organizational aims of the process itself (Komporozos-Athanasiou and Thompson 2015, 1144-1145). It all turns to a slanging match (Barnes 2008, 473). The feelings and dispositions of listeners, of the ones receiving emotional messages, are not to be neglected: The passionate deliberative discourse requires emotion work from the audience; listeners can even feel humiliated at a certain moment in time and this can lead to exclusion. This is why authentic emotions are often welcome, but some situations require them to be "kept hidden" (Saam 2018, 759-760).

On the other hand, expressing passion during a public debate can lead to benefits, in terms of argumentation accompanied by reason and understanding (Saam 2018, 758). It can also positively contribute to the inclusion of the ones affected by decisions: These people have to benefit from the moral right of expressing opinions passionately - a natural type of human interaction (Barnes 2008, 469; Martin 2012, 166; Davies, Wetherell and Barnett 2006; Young 2000). Resuming discussions to reason, substance, neutrality or a dispassionate engagement means people cannot manifest themselves: "Traditionally disengaged citizens" are discriminated (Campbell 2005, 698). Secondly, people may have "experienced unfairness and injustice" (Barnes 2008, 473) and, in their search for equitability, emphasize their hurt using a loud and determined voice. 
It is a way of "personal investment in the discourse" (Martin 2012, 173), which adds value to the debate, by conferring a necessary degree of vitality - supposed not to disturb, but in the end to facilitate and substantiate the process, secure it with understanding: "Emotions provide important information that policy makers need to recognize in determining what action is necessary in order to produce positive outcomes" (Barnes 2008, 476).

Inclusion and understanding are thus two main elements contributing to a proper political communicative process, to positive outcomes and a consensus more likely to be achieved. Then again, if allowing people to manifest their emotions means inclusion and understanding, an exaggerated permissiveness marginalizes the ones prepared to state their opinions (Martin 2012, 167; Barnes et al. 2007): When they feel discussions are too emotive, citizens may become discouraged and withdraw from the deliberative practice.

\subsubsection{The emotional balance}

An expressive and meaningful dispute, meant to invigorate discussions, has to be allowed, instead of concentrating on a solely neutral debate. The strategy is part of the so-called "emotional morality" (Barnes 2008, 473). The powerful tone of discussions and the so-called appeals to affect (March 2013, 535), to the feelings of the listener - emotional arguments based on intimacy and profundity - are important; they provide understanding and inclusion for citizens who usually stay aside. However, given the reasons above, it is not advisable to have discussions fully charged with emotion, but to approach them in an eventempered manner. Likewise, passionate discourses should not be based on individual claims, but "express a position that is shared by many others" (Barnes 2008, 473); the collective orientation of emotional claims thus provides them with a certain degree of authenticity and legitimacy. Dryzek $(2000,1)$ resumes: "persuasion, rather than coercion, manipulation, or deception". Accomplishing these requirements allows us to speak about an emotional balance for our deliberation. The strategy is applicable in the case of citizens (participants, beneficiaries) and officials, alike. Organizers of public debates may 
"exercise power" by setting "boundaries" to the discourse (Hodge 2005). They can use their positions for manipulating the course of discussions and exclude opinions which do not conform to their purposes. Komporozos-Athanasiou and Thompson $(2015,1140)$ call it managerial manipulation of laypeople: "The organization seeks to control emotion and delineate boundaries within which it is allowed to surface".

The emotional balance should be a purpose for all parts involved in the process. Accomplishing it is theoretically possible. In practice, organizers have to be open to a "diverse range of discursive styles and subject positions" (Martin 2012, 167). Describing a concrete situation following his observations on a deliberative forum, Martin $(2012,176)$ resumes: "This, then, was no Habermasian 'ideal speech situation' (...) in which the power of the best argument held sway: rather it was a forum where some participants were more vociferous and persuasive than others".

\subsubsection{The moral balance}

If the excess of emotional discourse can lead to coercion and manipulation, an exclusive use of moral arguments in a public debate can have similar negative effects. Basically, moral arguments facilitate a moral agreement (Gutmann and Thompson 1996; Barnes 2008). And this reconciliation can be an important stage for passing to a cognitive and legal consensus - necessary for achieving the goals of deliberation: "welfare, well-being and justice" (Barnes 2008, 461-462). Moral and religious points of view are welcome, they often prove "non-theocratic, respectful, and justice promoting" (March 2013, 524), sometimes even more plausible / less controversial than secular utilitarian ones (Weiberg-Salzman and Willems 2020, 9). For legitimizing the deliberative process, moral argumentation has to be, however, supplemented by an "enlightened", substantive type of discourse. The term "common reason" is used for describing the fundament of decision making in the liberal, democratic society (WeibergSalzman and Willems 2020; Barbato 2011; Habermas 2005). "Public reason" and "public good" further come into question when talking about the means, 
respectively the goal one should not disregard when introducing religious arguments into equation: We should "give properly public reasons to support the principles and policies our comprehensive doctrine is said to support" (Rawls 1997, 776). Besides, the attitude of the speaker using religious arguments would have to show tolerance towards people of different denominations or moral persuasions, an effort to search for shared reasons, willingness to receive critical scrutiny and readiness for defeat (George 1997; Eberle 2002; Clanton, 2009; March 2013, 526).

Using rational, beside moral arguments, and tolerating contrary positions sustain a "moral acceptability of presenting religious arguments in public" (March 2013, 526): An inclusive, permissive and normative attitude - keeping the discourse out of an exclusively rational trajectory, but directed towards common reason - will help in achieving a necessary moral balance for the deliberative practice.

\subsection{An ethical and effective deliberation}

Maintaining a balance from a moral and emotional point of view is often only possible by means of "pragmatic compromises" (Martin 2012, 179). But it also depends on considering some specific policies: First of all, public officials and participants have to be competent; Webler (1995) speaks about cognitive competence and Dryzek $(2000,1)$ mentions the presence of eligible, learned citizens in the process. Cognitive competence, knowledge of the subject, has to be doubled by an "affective competence" - commitment, engagement with counterparts, receiving and responding to emotions and personal experiences in such a way that people finally feel "their contributions are recognized and valued" (Barnes 2008, 476). Moreover, public officials would have to show attentiveness, responsiveness and responsibility when dealing with participation (Barnes 2008; Tronto 1993; Sevenhuijsen 1998); these qualities can provide trust - the final balancing element, able to assure a relational ethics and an effective deliberative process (Barnes 2008, 474; Barnes and Prior 1998). 


\section{METHODS}

For verifying these theoretical elements, we partially used the personal participatory observation and interpreted the document containing the written record of the public meeting in question. From the position of the moderator, we have observed the event from the beginning to the end: Involvement in the field enables a better understanding of the data (e.g., Strübing 2013, Breidenstein et al. 2013; Martin 2012, 170). Participation in the social practice as a (neutral) actor, not an external observer or a researcher, facilitates an in-depth view on the process, due to the already established contacts to the milieu. Our participatory presence in the field was important, it gave us access to the setting and a valuable insider perspective, but the essential method used in this study remained the analysis of the written document of the meeting.

A limitation of this research - counterbalanced by the relevant character and content of the deliberative event, for the subject - derives from the fact that the present paper is written after 13 years since the public debate took place. Memories fade out and details related to behavioural elements, which could describe the emotional factor better, are present to a lesser extent. We did not have access to audio- or videotaped materials of the meeting, so we relied on the written transcription of discussions and our personal recollections. "Inclusion of more explicit emotional analysis may encourage techniques such as ethnography, personal recollection, diaries, interviews and storytelling (e.g.) in deliberation studies"; the reflexivity of the researcher is very important here, as she is "inevitably drawn into the study herself" (Komporozos-Athanasiou and Thompson 2015, 1149). This reflexivity refers to a personal view on the practice from the researcher, after leaving the field and beginning to analyse her data. She has to detach herself from previous experiences and turn to an (as much as possible) objective evaluation.

We are presenting this public debate in a narrative manner, focusing on the statements coming from participants, respectively on the degree of emotionality and the religious character of their arguments. Our chosen predominant analytical strategy - the conversation and discourse analysis - was determined by a given quality and consistency of the applicable document: The word for 
word transcription contains all dialogue scenes and dozens of meaningful statements, allowing a relevant interpretative approach. Applied methods of dramaturgical, conversation and discourse analysis are particularly mentioned in the literature and made use of when it comes to evaluating public participation exercises (e.g., Carvalhoet al. 2019; Harvey 2009). The dramaturgical approach is based on studying the event as a whole, from the perspective of interactions and the roles played by each actor in producing the rituals. Discourse analysis is less concerned with an individual type of rhetoric and refers to a broader manner in which language is used "to construct the problematic in a certain way over other possible ways" (Harvey 2009, 154). Then again, interpreting conversational aspects means looking at interactions - and at the lexical choice of participants (Harvey 2009, 152-154): This type of approach focuses on the manner in which social actors "make sense of and respond to one another" in the frame of the so-called "talk-in-interaction" (Lester and O'Reilly $2019,4)$. The interpretation in this paper finally combines the discourse and conversation analysis, to evaluate the extent to which the passionate religious discourse during the deliberative event was able to provide inclusion, reasonable understanding and an effective participation.

\section{THE CASE STUDY}

The participatory event analysed in this article was held in 2007 at the City of Timișoara, in Romania. Gathering around 200 people, the debate comprised dozens of religious and nonreligious arguments, related to the appropriateness of constructing a church in a central neighborhood. These were shared between clergy, administration and citizens - for their most part, inhabitants in the area. Representatives of the Church brought historical arguments into discussion, in favour of building the chapel in that particular neighborhood; they claimed the need for more places of worship, for the (around 90\%) majoritarian Orthodox population, as no churches had been built in the decades of authoritarian communist rule. Most of the ones positioned against the initiative, on the other side, underlined the spatial argument (inappropriateness of the location) and the 
potential discomfort of future construction works. Discussions focused on the importance of religious education and a Christian shaped environment for young people, who should not be kept away from the church. Some of the attendants made connections to values of the European Union (which Romania had just joined), like dialogue and public transparency. Passionate debates finally arose around the person of the priest himself nominated to look after the construction and put in charge of the future parish. Although the majority supported him and his missionary activity, some opponents accused him of taking decisions without consultations: "His conscience knows why he insists building the church in that particular place" (Record of the public debate from 18.01.2007, City of Timișoara). The person asked the public to forgive him, for telling the truth. We here deal with a kind of "conscience to conscience" appeal, as a culminating point of the meeting; the speaker seemed to possess information which others were not invested with, did not want to give birth to a perhaps even bigger scandal by revealing his knowledge, instead modestly calling on moral arguments: "I bow before you, Father, I know you have done wonderful things and built wonderful churches; nevertheless in this case, you should have asked us first" (Record of the public debate from 18.01.2007, City of Timișoara). The general impression of the ones opposing the project was that Church and administration colluded in pursuing a certain interest. Whereas some turned to loudness and radicalism, others used sophisticated methods: We mentioned, for instance, the person who appealed to the "power of conscience" and apologized "for telling the truth". Although the feeling of guilt should not have played any part in this situation (do we at any time have to feel guilty for telling the truth?), the high level of emotion, on one hand, an obviously overaveraged educational level and a certain degree of natural fear for possible consequences of his statements all contributed to this "humble" type of offense. Public officials and local politicians confined themselves to observing discussions and described them as part of a positively developing democratic process. The chief-architect explained the legal structure of the initiative and politicians (local councilors), who were to take the decision, committed to an analysis of the documentation and to finding another location for the construction, if this was possible and would have eliminated contradictions. The 
dispute finished with the intervention of Church representatives: Supporting the project, they directed towards dialogue, as a key element in finally solving the issue. Some of them underlined the proposed location as the only solution available, while others left the door open for negotiations. Overall, the dialogue tended to come across legal appropriateness and turned several times to moral and religious values to be taken into consideration. It was an emotionally loaded debate, with discussions carried out on a determined and passionate tone of voice. They were interrupted several times with appeals for a civilized discourse and had to be paused once, so spirits could calm down. After initially approving the project, the Local Council retracted its decision and a more proper place for the construction could be found one month later in the same neighborhood, several hundred yards further.

\section{RESULTS}

The analytical interpretation shows the presence of the three precursors for a functioning democratic system - inclusion, effective participation and enlightened understanding - during the public debate. In this section, we will detail the unfolding of the meeting on a narrative basis. We use conversation and discourse analysis for interpreting the discussions from the point of view of their emotional and religious character, respectively intend to evaluate the impact of the passionate religious discourse on reaching an agreement and ensuring the goals of deliberation - welfare, well-being and justice.

\subsection{Including the disengaged}

Participants had the possibility of permanently expressing their views during this public debate - and they did it either neutrally, in favour of building the edifice, or against the construction. Our participatory observation revealed that emotions and religious arguments were allowed to enter the scene and unfold in an undisturbed manner, which ensured a significant degree of inclusion for the 
deliberative process - as no person was blocked from stating her or his opinion on the subject. Emotions came with a considerable degree of personal engagement from the side of participants, who expressed their feelings towards the situation: "It is the most agitated debate from many I have attended; let us not cause a scandal around the Church", said one of the politicians attending discussions. Indeed, he has had the opportunity to witness many debates in that period of particular focus on decisional transparency in Timișoara; as a result of a recent law, authorities were preoccupied to constantly publish all their projects and invite citizens and civil society to state their opinions. The particularity of this debate, from an emotional point of view, is emphasized by fellow participants, too: “I am sorry for the emotions, I didn't believe we were coming to this...", "I am living a nightmare for one month, generated by the ambitions of a person who should wish for peace and understanding among humans", "I am the economic councilor of the metropolitanate, I am sorry, I am overwhelmed with emotion, too" (Record of the public debate from 18.01.2007, City of Timișoara). These are only a few discursive elements confirming per se the tense atmosphere in the room.

Besides these direct statements, emotionality was perceptible by the observer in the tonality of discussions. The two sides countered each other on a vociferous tone, murmuring almost each time opponents said something considered disturbing. The passionate interest for the subject is to be already tracked down with the first person who takes the floor: "I want to tell you from the beginning that I am not against building a church in my neighborhood, but, just like... thank you". He continues after a few seconds of break, impelled by people talking at the same time. A following female inhabitant tries to be more convincing: "Don't move anything from that place! We'll fight for building the church somewhere else. There are hundreds of children who need recreation. Take my life at this right moment, but do not touch that park!" Coercion, manipulation, blackmail? Or, rather, a manifestation of despair, from someone who had lived there for decades and was merely trying to conserve what she and many others viewed as part of their everyday life. Her vociferous tone expresses an intense frustration upon possible implications - "unfairness and injustice". In a desperate search for equitability, she brings herself in front, 
hoping that someone will take account of this drama. The moderator allows the participant to state her opinions and intervenes in the end: "Thank you and we would like to ask you to keep a limit of decency with the tone we are using" (Record of the public debate from 18.01.2007, City of Timișoara).

This is just one example of a strong personal investment in the discourse. This particular speaker can be seen as a representative of the adversaries and her inclusion in the debate was a benefit for the process; she had been living in the area for a long time and possessed a cognitive competence to deliberate on the particular subject. Her agitation was determined by the potentially harmful direct impact of the construction upon the children in the area. She was the one taking care of that playground; it was not an individual concern, but a collectively addressed one. All these elements contribute to a certain degree of emotional balance; they authenticate and legitimize her discourse, make her emotional attitude recognizable to policy makers and contribute to the inclusiveness (rather than disturbance) of the communicative process.

We will offer only a few more examples showing the tense atmosphere in the room, due to a high tone of voice and the fact that people could not refrain from intervening and disrupting discussions. Above all, appeals to affect were meant to vitalize the debate and personalize the subject. "How can someone become deaf from a poor bell? I consider the opponents' aggressive arguments unreasoned and malicious: Why can't someone see a church in front of their eyes?". After hearing vociferous reactions in the room, the moderator needs to intervene again, asking participants to act in a civilized manner: "I do not think I have to remind you that we are living in Timișoara, renowned for its civic spirit, and I would not like us to embarrass ourselves". The profundity of arguments and their power of expression drove the discourse towards subjectivity and intimacy: "Ask your conscience if God does not deserve an effort or a sacrifice from you", "Jews preferred Barabbas, what have I done for God?", "A church emanates light", or "Christ sacrificed himself out of love" - are some of the most emotionally loaded affirmations with religious connotation, belonging to citizens and Church representatives alike (Record of the public debate from 18.01.2007, City of Timișoara). These passionate statements turn to a moral and religious argumentation in a laic and rational context - the appropriateness of a 
building in a particular living area. One of the participants summarizes the nonreligious character of the subject: "We are not in war with the Church; we just want some other location". Finally, the fact that people had the unrestrained opportunity to express these opinions in a highly emotional manner, at the same time using moral and religious arguments, reveals a significant level of inclusion for the deliberative practice.

\subsection{The "enlightened" understanding}

Under the circumstances, the need for "public reasons to support the principles and policies our comprehensive doctrine is said to support" was certainly being felt. We now enter the field of what we have called moral balance. There were supporters of the initiative who came with arguments referring to the public good: "Maybe you will be kinder and more loving to members of your families, maybe children will be better educated; playground and resting places will be relocated in the church courtyard...". They combined the religious and laic argumentation for projecting an ideal image of a situation that would satisfy everyone. "The priest will take care of the green area, too", said one of the participants, whereas others referred to potential beneficiaries of the project: "Believers are quiet and civilized; we should have more peace here". It was not only about emotionally expressed doctrinal principles anymore, it was about making the religious discourse morally acceptable, by providing it with rational supporting elements.

The discursive emotional and moral balance interfere, they cannot be entirely separated: The level of voice used during conversations, the power of expression and the (moral or rational) character of argumentation are interconnected; they have to be focused on persuasion and avoid slipping towards coercion, manipulation and deception. A relative balance to this respect confers reasonable understanding to the deliberative process and facilitates a consensus. 


\subsection{Ethics and effectiveness}

We remember the specific policies needed to be taken into consideration for reaching a moral and emotional balance, respectively assuring an effective deliberation - cognitive and affective competence, attentiveness, responsiveness and responsibility. To what extent were people in this particular case willing to conform to relational ethics, in order for the discourses to remain authentic and, despite moral and passionate arguments, not turn to a manipulative, unreasonable slanging match? First of all, cognitive competence was to be observed not only at attending officials (specialists in urban planning), but also at citizens: "We have a $1100 \mathrm{~m}$ total surface and the edifice occupies $236 \mathrm{~m}$. The rest will be a park", "I was convinced of the feasibility after I saw the placement diagram". Many of them demonstrated they have read and analysed the project, knowingly bringing its details into discussion. Affective competence, on the other side, meant tolerance for emotional behaviour and different religious or moral opinions, acceptance of criticism and willingness to compromise. The chief-architect of the City mentioned he was analysing the situation from a professional perspective: "The documentation made us think that this is the best solution. I would agree to this plan; however, this is not what's important". What was important, he said, was being able to witness a public debate "with a full room", calling it a democratic exercise and a "sign of maturity". He underlined he was not in charge of refereeing the social factor and taking a decision, but will consider all the arguments expressed by participants (Record of the public debate, 18.01.2007, City of Timișoara). The Church was also open for further discussions: "We do not want it necessarily here; let us not fight against each other. Invite us to discussions; we are open to other solutions, to reach peace among us". Tolerance and compromise were the signs through which both institutions involved in the deliberation - Church and administration - demonstrated affective competence, needed for beneficiaries to finally feel "their contributions are recognized and valued". Disposition towards compromise was also a sign of responsibility from the ones able to take a decision. Finally, there were attempts from public officials to regain the important element of trust, which seemed lost during discussions: "A technical 
committee, formed by specialists outside the administration, approved this location" and "We tried to ensure legality, transparency and professionalism" (Record of the public debate from 18.01.2007, City of Timișoara).

Consideration for these ethical principles allowed the discussions to be kept in a balance, from a moral and emotional point of view: a necessary condition for reaching effectiveness and, finally, the goals of the deliberation: welfare, wellbeing and justice.

\section{CONCLUSIONS}

The aim of this paper was to evaluate the degree to which an emotionally loaded religious discourse can have an impact on the outcomes of a deliberative process at the local governance level. The research question was related to the extent to which religious arguments, presented in a passionate manner, are able to ensure inclusiveness, provide the deliberative process with substance and contribute to effectiveness, in terms of reaching an acceptable agreement. Methods were based on an analytical strategy, containing the discourse and conversational analysis of a public debate held in 2007 at the City of Timișoara, Romania.

Literature mainly regarded emotions, as well as moral and religious arguments, as potentially disturbing a public communicative process, and marched on the importance of the substantive, enlightened, rational manner of communicating, or presenting their arguments, from the side of participants involved in a public debate. Building public policies inside local governance systems is a complex process, which often confronts with more than the reasonable "ideal speech situation", where the force of the better argument prevails. In a liberal democracy, rather the individuality of people's characters, personalities and emotions comes into question. And then, politicians, public officials, moderators of the deliberative process, have to pursue a moral and emotional balance - not exclude potential vociferous participants expressing moral and religious arguments, and at the same time maintain a consistent level of "enlightened understanding" or rationality - thus keeping the chance for the deliberation to become effective and reach acceptable results. Otherwise, we can deal with 
exclusion, lack of rationality, and of a tangible outcomes - with welfare, wellbeing and justice far from being accomplished.

The analytical interpretation of the way this public debate unfolded, of the manner in which people were allowed to state their opinions (inclusion), of the emotional and rational character of discussions (understanding) and of the results in terms of reaching an acceptable agreement (effectiveness) - show that religious passionate rhetoric can definitely contribute to strengthening democracy at local governance level: Neutrality and objectivity are necessary for achieving an emotional balance; supplementing the moral frame of discourse with rational arguments can, further, lead to a moral balance for the deliberative practice. Emotion and moral arguments on one side, neutrality and reason on the other, are complementary and often overlap: For an ethical and effective deliberation, they have to be, responsibly and competently, taken into consideration together.

Our findings are the expression of an in-depth analysis of a local, particular social practice. Their relevance comes from adding to an under-explored research field - of emotion and religious argumentation in decision-making processes at local governance level - and from establishing the importance of a morally and emotionally balanced approach for the effective outcomes of a deliberative process. The paper`s implications on a more general scale are related to highlighting the importance of deliberation as part of the larger political communication area, and its vital role in a democratic society - either with reference to nations, regions, or local communities: Communication is a major component of politics and the analysis of the way it is being conducted inside deliberative processes can lead to a deeper understanding upon the democratic degree of a certain governance system. Future research can extend the subject and the methods used for gaining the data: By means of interviews and group discussions - look at "the important dimension of each participant's own qualitative experience" (Harvey 2009, 146). That is, observing, interpreting and (on a double hermeneutical basis) understanding a public deliberation event, through the eyes of attendants: with focus not on the process itself, but on the manner in which individual emotions take shape and in which participants perceive and describe their feelings. 


\section{ACKNOWLEDGEMENT}

I am thankful to the City of Timișoara, for having the chance to moderate several debates as a public employee around the time the event described here had happened. It was an opportunity to learn about civic involvement, the practice of dialogue and appropriate solutions to be applied in difficult communicative situations.

\section{REFERENCES}

- Barbato, Mariano. 2011. "Auf der Suche nach einer postsäkularen «Lingua Franca»? Die postsäkulare Gesellschaft von Jürgen Habermas am Beispiel der parlamentarischen Debatte zur Spätabtreibung" [On the search for a postsecular "Lingua franca"? The postsecular society of Jürgen Habermas using the example of the parliamentary debate on late-term abortion]. Liedhegener, Antonius, and Ines-J. Werkner (eds). Religion zwischen Zivilgesellschaft und politischem System: Befunde-Positionen-Perspektiven [Religion between civil society and political system: results-positions-perspectives]. Wiesbaden: VS. 56-77.

- Bächtiger, André, and John R. Parkinson. 2019. Mapping and Measuring Deliberation: Towards a New Deliberative Quality. Oxford, UK: Oxford University Press.

- Barber, Benjamin R. 1984. Strong Democracy: Participatory Politics for a New Age. Berkeley: University of California Press.

- Barnes, Marian. 2008. "Passionate participation: emotional experiences and expressions in deliberative forums". Critical Social Policy. 28(4): 461-481.

- Barnes, Marian. 2005. "Same Old Process? Older People, Participation and Deliberation". Ageing and Society .25(2): 245-59.

- Barnes, Marian, and David Prior. 1998. "Trust and the Competence of the Welfare Consumer". Coulson, Andrew (ed.). Trust and Contracts: 
Relationships in Local Government, Health and Public Services. Bristol: Policy Press,. 129-42.

- Barnes, Marian, Janet Newman and Helen Sullivan. 2007. Power, Participation and Political Renewal: Case Studies in Public Participation. Bristol: Policy Press.

- Breidenstein, Georg, Stefan Hirschauer, Herbert Kalthoff and Boris Nieswand. 2013. Ethnografie. Die Praxis der Feldforschung [Ethnography. The praxis of field research]. Konstanz and München: UKV.

- Campbell, Kelly B. 2005. "Theorizing the Authentic: Identity, Engagement, and Public Space". Administration \& Society. 36(6): 688-705.

- Carvalho, Anabela, Zara Pinto-Coelho and Eunice Seixas. 2019. “Listening to the Public - Enacting Power: Citizen Access, Standing and Influence in Public Participation Discourses". Journal of Environmental Policy \& Planning. 21(5): 563-576.

- Clanton, Caleb J. 2009. “Democratic Deliberation after Religious Gag Rules". In: Caleb Clanton, J. (ed.) The Ethics of Citizenship: Liberal Democracy and Religious Convictions. Waco, TX: Baylor University Press.

- Dahl, Robert. 1989. Democracy and its critics. New Haven: Yale University Press.

- Davies, Celia, Margaret Wetherell and Elisabeth Barnett. 2006. Citizens at the Centre: Deliberative Participation in Health Care Decisions. Bristol: Policy Press. 2006.

- Davies, Celia, Margaret Wetherell and Elisabeth Barnett. 2009. "A Citizens Council in the Making: Dilemmas for Citizens and their Hosts". Littlejohns, Peter, and Michael Rawlins (eds). Patients, the Public and Priorities in Healthcare. Abingdon: Radcliffe Publishing,. 129-38.

- Dryzek, John. 2000. Deliberative Democracy and Beyond: Liberals, Critics, Contestations. Oxford, UK: Oxford University Press.

- Eberle, Christopher J. 2002. Religious Conviction in Liberal Politics. Cambridge University Press. 
- Engelken-Jorge, Marcos. 2011. "Politics \& Emotions: An Overview". Engelken-Jorge Marcos, Pedro Ibarra Güell, and Carmelo Moreno del Río (eds). Politics and Emotions. Wiesbaden: VS Verlag für Sozialwissenschaften.

- Gastil, John. 2008. Political Communication and Deliberation. Thousand Oaks, CA: Sage Publications, Inc.

- George, Robert P. 1997. Law, Democracy, and Moral Disagreement. Harvard Law Review. 110(7): 1388-406.

- Gutmann, Amy, and Dennis F. Thompson. 1996. Democracy and Disagreement. Cambridge, MA: Belknap Press.

- Habermas, Jürgen. 2005. Zwischen Naturalismus und Religion: Philosophische Aufsätze [Between naturalism and religion. Philosophical essays]. Frankfurt a.M.: Suhrkamp.

- Habermas, Jürgen. 1975. The Legitimation Crisis of Late Capitalism. trans. T. McCarthy. Boston, MA: Beacon Press.

- Habermas, Jürgen. 1970. "Toward a theory of communicative competence". Inquiry. 13(4): 360-75.

- Harvey, Matthew. 2009. "Drama, Talk, and Emotion. Omitted Aspects of Public Participation". Science, Technology \& Human Values. 34(2): 139-161.

- Hodge, Suzanne. 2005. "Participation, Discourse and Power: A Case Study in Service User Involvement". Critical Social Policy. 25(2): 164-79.

- Hoggett, Paul, and Simon Thompson. 2002. "Toward a democracy of the emotions". Constellations. 9(1): 106-26.

- Komporozos-Athanasiou, Aris, and Mark Thompson. 2015. "The role of emotion in enabling and conditioning public deliberation outcomes: a sociological investigation". Public Administration. 93(4): 1138-1151.

- Lester, Jessica N., and Michelle O'Reilly. 2019. Applied Conversation Analysis. Social Interaction in Institutional Setting. SAGE Publications, Inc.

- List, Christian. 2018. "Democratic Deliberation and Social Choice: A Review". Bächtiger, André, Dryzek, John S., Mansbridge, Jane, and Mark Warren (eds.). The Oxford Handbook of Deliberative Democracy. Oxford, UK: Oxford University Press. 
- March, Andrew F. 2013. "Rethinking Religious Reasons in Public Justification". The American Political Science Review, 107(3): 523-539.

- Martin, Graham P. 2012. "Public deliberation in action: Emotion, inclusion and exclusion in participatory decision making". Critical Social Policy. 32: 163-83.

- Rawls, John 1997. "The Idea of Public Reason Revisited". The University of Chicago Law Review. 64(3): 765-807.

- Record of the public debate from 18.01.2007, City of Timișoara - retrieved from https://www.primariatm.ro/transparenta/dezbateripublice/dezbateri-publice-in-2007/.

- Saam, Nicole J. 2018. "Recognizing the Emotion Work in Deliberation. Why Emotions Do Not Make Deliberative Democracy More Democratic". Political Psychology. 39: 755-773.

- Sevenhuijsen, Selma. 1998. Citizenship and the Ethics of Care: Feminist Considerations on Justice, Morality and Politics. London and New York: Routledge.

- Smith, Graham. 2009. Democratic Innovations. Designing institutions for citizen participation. Cambridge, UK: Cambridge University Press.

- Strübing, Jörg. 2013. Qualitative Sozialforschung [Qualitative social research]. München: Oldenbourg Wissenschaftsverlag.

- Thompson, Simon, and Paul Hoggett. 2001. "The Emotional Dynamics of Deliberative Democracy". Policy and Politics. 29(3): 351-64.

- Tronto, Joan C. 1993. Moral Boundaries: A Political Argument for an Ethic of Care. New York and London: Routledge.

- Waldron, Jeremy. 2002. God, Locke, and Equality: Christian Foundations in Locke's Political Thought. Cambridge, UK: Cambridge University Press.

- Waldron, Jeremy. 2012. "Two-Way Translation: The Ethics of Engaging with Religious Contributions in Public Deliberation". Mercer Law Review. 63(3): 845-68.

- Weiberg-Salzmann Mirjam, and Ulrich Willems. 2020. "Challenging the Political: Religious Actors and Religious Arguments in Liberal 
Democracies". Weiberg-Salzmann, Mirjam, and Ulrich Willems (eds). Religion and Biopolitics. Springer, Cham.

- Webler, Thomas. 1995. "«Right» Discourse in Citizen Participation: An Evaluative Yardstick". In: Renn, Ortwin, Thomas Webler, and Peter Wiedemann (eds) Fairness and Competence in Citizen Participation: Evaluating Models for Environmental Discourse. Dordrecht: Kluwer Academic Publishers. 35-86.

- Young, Iris M. 2000. Inclusion and Democracy. Oxford, UK: Oxford University Press. 